\title{
Cianosis en un paciente de 14 años. Presentación de un caso de metahemoglobinemia
} Cyanosis in 14-year-old patient. Methemoglobinemia: case report

\author{
Dra. Marina Orlandia, Dra. María A. Amadi ${ }^{a}$ Dr. Pablo X. Goldaracena y Dr. Federico E. Pérez ${ }^{a}$
}

\section{RESUMEN}

La cianosis es la coloración azulada de la piel y las mucosas debida al aumento de la concentración de hemoglobina reducida en los capilares o a la presencia de metahemoglobina en concentraciones mayores delas normales. Es importante pensar en metahemoglobinemia como diagnóstico diferencial frente a un paciente con cianosis que no responde a la administración de oxígeno cuando no existen causas cardiorrespiratorias que la justifiquen, dado que requiere de otros métodos diagnósticos y de tratamiento específico. Se presenta el caso de un paciente adolescente de 14 años de edad con cianosis secundaria a metahemoglobinemia de probable etiología congénita. Se discuten las causas, forma de presentación, diagnóstico y tratamiento.

Palabras clave: cianosis, metahemoglobinemia, intoxicación, pediatría, oximetría de pulso.

\begin{abstract}
The bluish coloration of skin and mucous membranes, called as cyanosis, could be explained by high reduced hemoglobin in the capillaries, or the presence of elevated methemoglobin concentration.

It is important to think of methemoglobinemia as a differential diagnosis in a cyanotic patient who does not respond to oxygen administration once cardiorespiratory causes are discarded; since it requires other diagnostic methods and specific treatment. We described a case of cyanosis in a fourteen-year-old adolescent with probable congenital methemoglobinemia. We discussed their probable causes, clinic presentation, diagnosis and treatment.
\end{abstract}

Key words: cyanosis, methemoglobinemia, intoxication, pediatrics, pulse oximetry.

http: / / dx.doi.org/10.5546/ aap.2018.e429

Cómo citar: Orlandi M, Amadi M, Goldaracena PX, et al. Cianosis en un paciente de 14 años. Presentación de un caso de metahemoglobinemia. Arch Argent Pediatr 2018;116(3):e429-e432.

a. Sala 3. de Internación de Clínica Pediátrica del Hospital de Niños Superiora Sor María Ludovica, La Plata, Buenos Aires.

Correspondencia:

Dra. Marina Orlandi: marinorlandi@hotmail.com

Financiamiento: Ninguno.

Conflicto de intereses: Ninguno que declarar.

Recibido: 12-7-2017

Aceptado: 22-1-2018

\section{INTRODUCCIÓN}

La cianosis es un signo clínico consistente en la coloración azulada de la piel y las mucosas debido a un aumento de la hemoglobina reducida en los capilares o a la presencia de metahemoglobina en cantidades superiores a las normales. ${ }^{1,2}$ Como signo clínico en pediatría, se manifiesta en gran variedad de enfermedades cardiopulmonares, que, una vez descartadas, harían pensar en otras causas sistémicas, entre ellas, la metahemoglobinemia. La hemoglobina tiene una estructura tetramérica formada por 4 cadenas de globina; cada una de ellas contiene un grupo hemo que incluye hierro en forma ferrosa. La hemoglobina que contiene hierro en forma férrica (metahemoglobina) no puede transportar oxígeno. ${ }^{3-5}$

La cianosis con falta de respuesta a la administración de oxígeno y el examen cardiopulmonar normal sugieren el transporte anormal de oxígeno por la hemoglobina. ${ }^{1,2,4,6}$

La metahemoglobina no tiene la capacidad de transportar oxígeno, por lo que los valores mayores de $1 \%$ o $2 \%$ provocan hipoxia tisular. ${ }^{1-3,6}$ Tiene un coeficiente de absorción de luz similar a la oxihemoglobina y a la hemoglobina reducida (desoxigenada) en las longitudes de onda a las que opera el pulsioxímetro, por lo tanto, sus valores serán confundidos con ambas fracciones y se obtendrán lecturas intermedias. ${ }^{6}$

Se presenta el caso de un paciente adolescente de 14 años de vida con cianosis secundaria a metahemoglobinemia de probable etiología congénita.

\section{CASO CLÍNICO}

Paciente de sexo masculino, de 14 años de edad, que ingresó por presentar una crisis continua de risa inmotivada asociada a la pérdida de la conciencia seguida de hipertonía generalizada. No presentaba antecedentes personales ni familiares relevantes.

Examen físico: paciente en buen estado general, lúcido, hemodinámicamente estable, sin signos de dificultad respiratoria. Como datos positivos, presentaba cianosis periorificial y 
acrocianosis, saturación de $79 \%$ con oxímetro de pulso, que no se revirtió al colocar oxigenoterapia al $100 \%$.

Se realizaron un electroencefalograma y una resonancia nuclear magnética de encéfalo, ambos de características normales, y se interpretó el episodio como crisis gelástica secundariamente generalizada.

El electrocardiograma, el ecocardiograma y la radiografía de tórax fueron normales, como así también la espirometría y el hemograma.

Los gases en sangre mostraron una presión parcial de oxígeno disuelto de 103 y dosaje de metahemoglobina mayor que el normal $(15,5 \%)$.

En búsqueda de la causa de dicha metahemoglobinemia, se reinterrogó al paciente y surgió el consumo de agua de pozo (en una zona cercana a un basural), la concurrencia del niño a una escuela agraria y el uso de ropa de color oscuro que le manchaba la piel.

Se indicó como tratamiento vitamina $\mathrm{C}$ a razón de $50 \mathrm{mg} / \mathrm{kg} /$ día intravenosa durante 8 días con descenso de la metahemoglobina a valores de 7,7\% (menor que el descenso esperado), por lo que se interpretó el cuadro clínico como de metahemoglobinemia de causa endógena (hemoglobinopatía o enzimopatía), y como medida preventiva realizar la descontaminación y evitar los factores desencadenantes, como aguas ricas en nitratos y medicamentos oxidantes.

Se realizó la electroforesis de la hemoglobina del paciente y sus familiares, que fueron normales, y el dosaje de metahemoglobina en su padre y su hermano.

Se interpretó al paciente como portador de metahemoglobinemia congénita, y no se pudo certificar el diagnóstico por carecer de la analítica para dosar la enzima citocromo b5 reductasa.

Continúa bajo seguimiento por el Servicio de Toxicología del Hospital con buena evolución y asintomático.

\section{DISCUSIÓN}

La metahemoglobina se forma a partir de la oxidación del hierro de la hemoglobina, que cambia de estado ferroso a férrico y desvía la curva de la oxihemoglobina a la izquierda con la consiguiente disminución de la afinidad de la hemoglobina por el oxígeno.

Normalmente, de $2 \%$ a $3 \%$ de la hemoglobina es oxidada diariamente a metahemoglobina. Los valores normales de metahemoglobinemia, expresados como porcentaje de la hemoglobina total, son de $1 \%$ en el adulto, de hasta $2 \%$ en los lactantes y de hasta $4 \%$ en los prematuros., $3,4,7,8$

La metahemoglobina reductasa (dinucleótido de nicotinamida y adenina reducida-nicotinamide adenine dinucleotide; NADH, por sus siglas en inglés- citocromo b5 reductasa) y la glutatión reductasa son las enzimas de mayor eficacia para reducir la metahemoglobina.

La forma congénita puede deberse a la presencia de hemoglobinas anormales, como la hemoglobina $\mathrm{M}$, que se hereda de manera autosómica dominante, o a la deficiencia de reductasas, de herencia autosómica recesiva. El gen regulador de la síntesis del citocromo b5 reductasa ha sido localizado en el cromosoma 22q13.

Según la clasificación clínica-bioquímica de Jaffe ${ }^{9}$ la metahemoglobinemia de causa enzimática se considera:

- Tipo 1: Es la más común y menos grave. Consiste en la deficiencia de citocromo b5 reductasa limitada a los eritrocitos. Los pacientes están "más azules" que enfermos y sus síntomas aparecen cuando los niveles de metahemoglobina exceden $25 \%$ de la hemoglobina total. Los síntomas frecuentes son cefalea, fatiga y disnea.

- Tipo 2: La metahemoglobinemia es más grave y se debe a una acentuada deficiencia enzimática de citocromo b5 reductasa, tanto de sus isoformas solubles como las unidas a membrana, que afecta a una multitud de tejidos, especialmente, el sistema nervioso central. La metahemoglobinemia congénita tipo 2 constituye el $10 \%$ de todos los casos

TABLA 1. Agentes oxidantes más frecuentes causantes de metahemoglobinemia

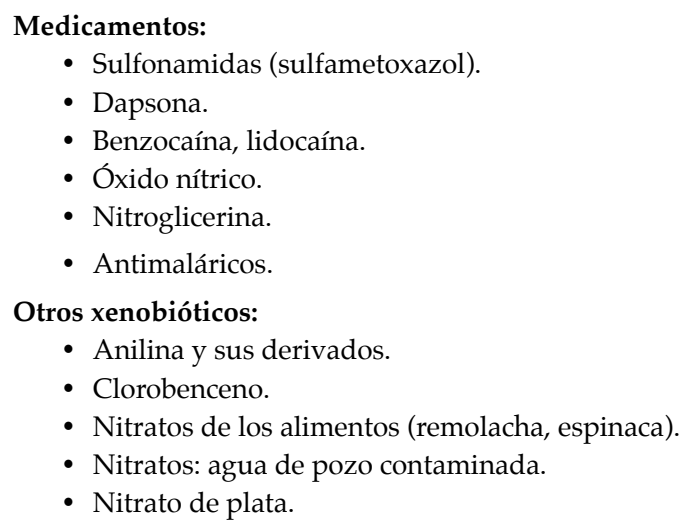

Adaptado de Goldfank's Toxicologic Emergencies. $9^{\text {th }} \mathrm{ed}$. United States. Mac Graw Hill; 2011:1698-1706. 
y suele ser fatal en los primeros años de la vida. Se caracteriza, sobre todo, por deterioro neurológico progresivo; se acompaña de retraso mental, microcefalia, opistótonos, movimientos atetósicos e hipertonía generalizada. La cianosis al nacer se asocia a trastorno neurológico y retraso mental. ${ }^{3-5}$

La forma adquirida es la más común y puede ser secundaria a procesos infecciosos que condicionan acidosis metabólica con liberación de radicales libres oxidantes y metahemoglobinemia (diarrea, infección, intolerancia a las proteínas de la leche, infección de vías urinarias, sepsis y acidemias orgánicas) o por ingestión o inhalación de algún agente oxidante. La exposición a medicamentos es la causa más común de metahemoglobinemia exógena en el niño mayor ${ }^{2,3}$ (Tabla 1).

Los recién nacidos y lactantes menores son más sensibles que los adultos a tóxicos que producen metahemoglobinemia, debido a que la hemoglobina fetal $(\mathrm{F})$ es más fácil de oxidar

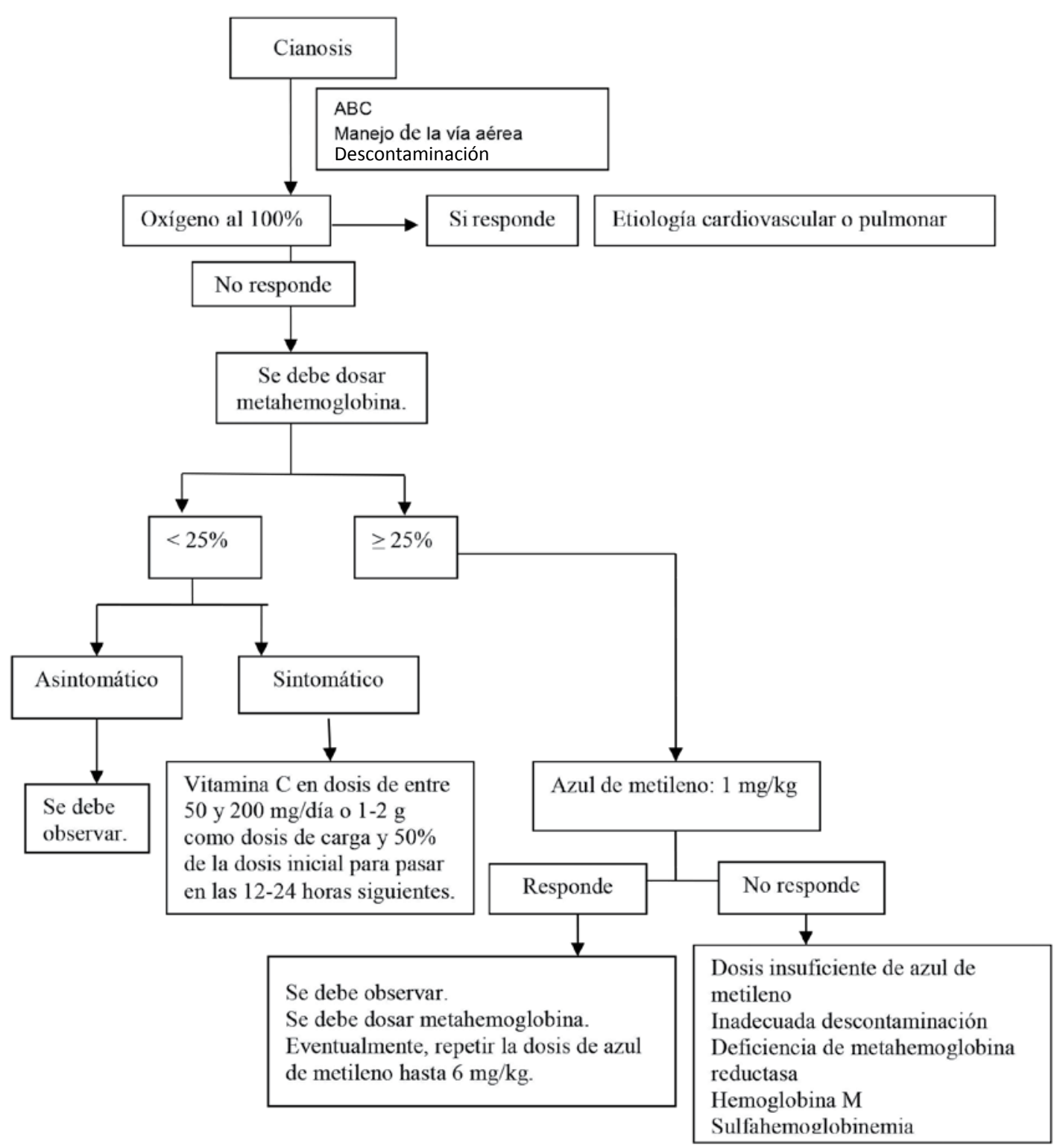


que la hemoglobina A (del adulto), el recién nacido tiene niveles más bajos de actividad de metahemoglobina reductasa, catalasa y glutatiónperoxidasa, el pH gástrico elevado facilita la proliferación bacteriana en el intestino delgado y se incrementa la conversión de nitratos de la dieta a nitritos por bacterias coliformes. ${ }^{6,8-13}$

Los lactantes menores de 6 meses alimentados con biberones preparados con aguas de pozos contaminadas con nitratos o alimentos de origen vegetal obtenidos de suelos ricos en fertilizantes tienen mayor riesgo de padecer metahemoglobinemia. Hervir el agua no elimina los nitratos; por el contrario, aumenta su concentración. ${ }^{8,9,12,13}$

La vida media de eliminación de la metahemoglobina es de 15 a 20 horas y los signos clínicos se normalizan en 24-72 horas.

Los pacientes que tienen niveles de metahemoglobina entre $10 \%$ y $15 \%$ presentan coloración azul violácea y coloración sanguínea "chocolate pardo" (la cual no cambia ante la exposición de oxígeno). Los niveles entre $15 \%$ y $40 \%$ producen cianosis generalizada, acúfenos, hiporexia, cefalea, irritabilidad, taquipnea, disnea, debilidad, vómitos, diarrea, letargia y síncope. Las cifras entre $40 \%$ y $50 \%$, acidosis y obnubilación. Los valores entre $50 \%$ y $70 \%$ ocasionan alteraciones sensoriales, depresión respiratoria, arritmias cardíacas, crisis convulsivas y coma. Las concentraciones mayores del $70 \%$ son letales. ${ }^{8}$

El tratamiento de la metahemoglobinemia consiste en el aporte de oxígeno al 100\% y en la administración de un agente reductor (ácido ascórbico o azul de metileno), según la gravedad. Con concentraciones menores del $15 \%$, no se realiza tratamiento; entre $15 \%$ y $25 \%$ (asintomáticos), se utiliza vitamina $\mathrm{C}$ en dosis de entre 50 y $200 \mathrm{mg} /$ día. En las moderadas o graves mayores del $25 \%$, se utiliza azul de metileno a razón de 1 a $2 \mathrm{mg} / \mathrm{kg} /$ dosis, diluido en dextrosa al 5\%, a pasar en 30 minutos, que pude repetirse 1 o 2 veces, con intervalos de 1 hora, según la evolución clínica y el descenso de las concentraciones de metahemoglobina. En las concentraciones $>30 \%$, sean sintomáticas o no, siempre se utiliza azul de metileno, cuya dosis no debe superar los $6 \mathrm{mg} / \mathrm{kg} /$ dosis, a partir de la cual se manifiestan signos de toxicidad, entre ellos, metahemoglobinemia. ${ }^{8}$ El seguimiento del paciente con cianosis se muestra en la Figura 1.

\section{CONCLUSIÓN}

En la infancia, la metahemoglobinemia debe ser sospechada en pacientes cianóticos que no responden al tratamiento con oxígeno y que no presentan alteraciones pulmonares o cardíacas. La coloración "achocolatada" de la muestra sanguínea es orientadora, además de la determinación de los niveles de metahemoglobina, saturación de oxígeno y gasometría arterial. Esta entidad debe tenerse en cuenta en el diagnóstico diferencial de un niño con cianosis y se debe estar familiarizado con sus posibles etiologías y tratamiento.

\section{REFERENCIAS}

1. Zárate-Aspiros R, Rosas-Sumano AB, Sánchez-Ramírez $\mathrm{AR}$, et al. Metahemoglobinemia congénita. Informe de un caso. Acta Pediatr Mex 2013;34(1):39-42.

2. De Rubens-Figueroa J, Jiménez-González ME, Francisco-Revilla EN. Cianosis como manifestación de metahemoglobinemia. Rev Med Inst Mex Seguro Soc 2008; 46(4):439-44.

3. Salinas JA, Corral H, Guibelalde $M$, et al. Metahemoglobinemia. Causa de cianosis en el niño. Acta Pediatr Esp 2010;68(3):143-5.

4. Ewenczyk C, Leroux A, Roubergue A, et al. Recessive hereditary methaemoglobinaemia, type II: delineation of the clinical spectrum. Brain 2008;131(Pte 3):760-1.

5. ToelleSP,Boltshauser E,Mössner E, etal.Severeneurological impairment in hereditary methaemoglobinaemia type 2 . Eur J Pediatr 2004;163(4-5):207-9.

6. Price D. Methemoglobin Inducers. In: Nelson L, Lewin N, Howland M, et al. Goldfrank's Toxicologic Emergencies. $9^{\text {th }}$ ed. New York: MacGraw-Hill; 2011.Págs.1698-706.

7. Larios Ortiz L, Cañas Pérez R, Sánchez Carmona A, et al. La contaminación del agua de pozo como causa de metahemoglobinemia en niños. Camagüey 1985-2001. Rev AMC 2004;8(2):29-41.

8. CabrerizoS.Contaminación hídrica. En:Sociedad Argentina de Pediatría PRONAP, 3; 2009.Págs.8-35.

9. Jaffe ER. Enzymopenic Hereditary Methemoglobinemia. Haematologia 1985;15(4):389-99.

10. Basulto J, Manera M, Baladia E. Ingesta dietética de nitratos en bebésy niños españolesy riesgodemetahemoglobinemia. Rev Pediatr Aten Primaria 2014;16(61):65-9.

11. Montalvo H, Azparren G, Castrillón S, et al. Methemoglobinemia detected during general anesthesia a case report. Eur J Anaesthesiol Suppl 2013;30(Suppl 51):48.

12. Calleros EY, Alarcón MT, Pérez R, et al. Evaluación de riesgo sistémico y niveles de metahemoglobina en niños que consumen agua contaminada por nitratos. Ingeniería 2012;16(3):183-94.

13. Greer FR, Shannon M. Infant Methemoglobinemia: The Role of Dietary Nitrate in Food and Water. Pediatrics 2005;116(3):784-6. 